\title{
Guaruman: a Natural Amazonian Fiber with Potential for Polymer Composite Reinforcement
}

\author{
Miriane Alexandrino Pinheiro ${ }^{a}$, Laercio Gouvêa Gomes ${ }^{b}$, Alisson Clay Rios da Silva ${ }^{a}$, Verônica \\ Scarpini Candido ${ }^{a}$, Raphael Henrique Morais Reis ${ }^{c}$, Sergio Neves Monteiro ${ }^{c *}$ [D \\ ${ }^{a}$ Departamento de Engenharia de Materiais, Universidade Federal do Pará, Belém, PA, Brasil \\ ${ }^{b}$ Departamento de Engenharia de Materiais, Instituto Federal do Pará, Belém, PA, Brasil \\ 'Programa de Ciência dos Materiais, Instituto Militar de Engenharia, Rio de Janeiro, RJ, Brasil
}

Received: February 01, 2019; Revised: May 08, 2019; Accepted: June 18, 2019

The Amazonian region of South America is known for its diversified number of plants from which food, medicine, wood and fibers have, since long time, been produced by local natives. A typical example is the guarumã ("guaruman"as suggested English spelling) scientifically identified as Ischinosiphon koem, an abundant plant found in the low lands alongside rivers of the state of Para in Brazil. Fibers extracted from the stem of the guaruman are used in ropes and baskets owing to their strength. In the present work, the possibility of applying guaruman fibers as reinforcement of polymer matrix composites is, for the first time, investigated. Amounts up to $30 \mathrm{vol} \%$ of continuous and aligned fibers were incorporates into epoxy matrix composites. Density measurements disclosed the guaruman to be one of the lightest natural fibers. Tensile tests indicate that the guaruman fiber addition was able to improve the composite elastic modulus. However, no significant change was found in the ultimate strength, total strain and resilience. On the other hand, a cost-effective analysis revealed a substantial reduction of $\sim 29 \%$ in the epoxy composite price due to the incorporation of fibers. Preliminary ballistic evaluation disclosed a potential for application of guaruman epoxy composites in multilayered armor.

Keywords: Guaruman fiber, epoxy matrix, natural fiber composite, tensile properties, cost-effective analysis.

\section{Introduction}

Natural fibers obtained from plants have been extensively investigated in past decades as reinforcement of polymer matrix composites. Indeed, since the beginning of this century, several review articles ${ }^{1-19}$ and books ${ }^{11-23}$ reported on an escalating number of published works dedicated to this subject. Metrics provided by the ISI - Web of Science indicate that only 94 papers with keyword "natural fiber" were published in the year of 2000. This number raised exponentially to 1,390 in 2018 to become one of the most relevant topics in the R\&D community. In practice, conventional synthetic fibers, mainly the glass fiber, are being gradually substituted for natural fibers in traditional composites applied in civil construction, furniture, commodity and automotive industries ${ }^{24-28}$. Among the reasons for technological interest in natural fibers stand the remarkable properties of some fibers as well as their market availability. In fact, some natural fibers such as flax, hemp, jute, sisal, cotton and ramie are worldwide cultivated. Their tensile strength surpasses $600 \mathrm{MPa}^{29}$, which is higher than most carbon steels ${ }^{30}$. Composite reinforced with these fibers might reach strength above $100 \mathrm{MPa}$ depending on the amount incorporated and specific polymer matrix ${ }^{18}$.

In addition to the traditional aforementioned natural fibers, others like coconut, pineapple, kenaf, banana, kapok, bamboo, abaca, isora, palm, henequen, sugarcane bagasse, piassava and many more ${ }^{19}$ are being investigated as possible composites reinforcement. Recent works ${ }^{31-34}$ also reported on the advantages of novel composites with banana fibers as well as sisal nanocomposites, fine textured sisal textile yarn and soy-based multifunctional materials. It should also be include those natural fiber available in specific countries such as agave (Mexico); fique (Colombia); date (Morocco) and curaua (Brazil). Actually, nature still preserves a huge number of other less known natural fibers waiting to be investigated as polymer composites reinforcement. This is the case of the guarumã fiber, here suggested to be spelled in English as "guaruman", typical of the Amazonian region. The fiber is extracted from the stem of the guaruman plant, scientifically known as Ischinosiphon koern, and illustrated in Fig 1.

Today, guaruman fibers are used by local people in the state of Para, Brazil, to fabricate ropes and baskets. Preliminary results on the tensile properties of these fibers indicate a potential for possible application as polymer composite reinforcement. Therefore, the objective of this work is to investigate for the first time the possibility of using guaruman fibers as reinforcement of epoxy matrix composites. Tensile tests of both plain epoxy and composite with up to $30 \mathrm{vol} \%$ of fibers were conducted to evaluate the potential of these composite for application in multilayered armor. A cost-effective analysis complements this investigation. 


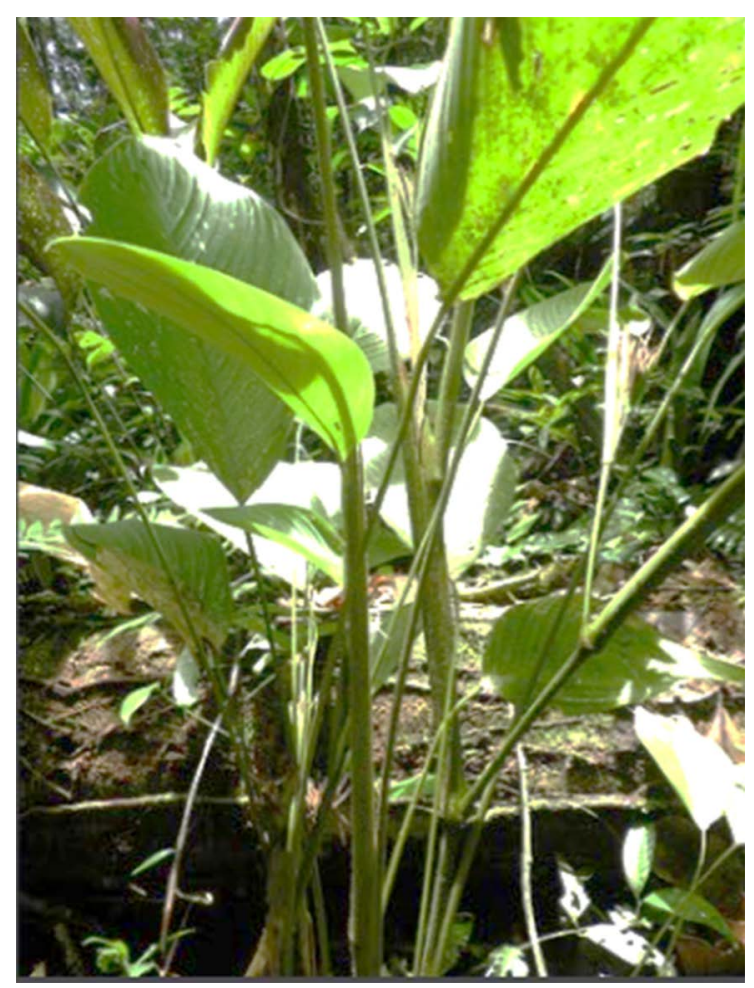

Figure 1. The guaruman plant.

\section{Experimental Procedure}

Guaruman stems were supplied by farmers located in the municipal area of Belem, state of Para, north of Brazil. Fibers were both mechanical and manually cut from the stems as illustrated in Figure 2.

The epoxy used as composite matrix was supplied by the retailer Veloz from Dow chemical as liquid diglycidyl ether of the bisphenol A (DGEBA) resin and triethylene tetramine (TETA) catalyst. Both were mixed in stoichiometric proportion at the moment of composite preparation.

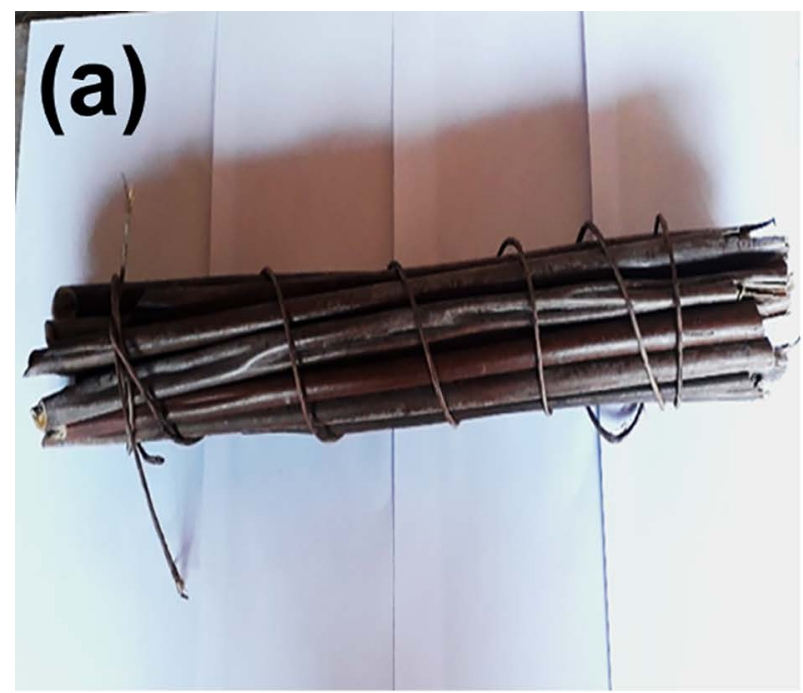

Fibers were cut with an average length of $100 \mathrm{~mm}$ and dried at $60^{\circ} \mathrm{C}$ to release moisture. The fibers diameter (d) was measured in a model Elipse LV150 Nikon optical microscope at 5 different positions along the axis of each fiber. By considering cylindrical fibers, their average density was determined by the mass divided by the volume $\left(\pi \mathrm{d}^{2} / 4\right)$. An analytical scale Bel, with $0.001 \mathrm{~g}$ of precision, was used to measure the mass $(\mathrm{m})$ of each fiber.

Based on the average density, amounts of 10, 20 and 30 vol $\%$ of guaruman fibers, with respect to the epoxy matrix, were used to fabricate dog-bone-shaped flat tensile specimens inside silicone molds. Figure 3 illustrates typical tensile specimens with guaruman fibers continuously aligned along the axis. In this figure, left side, it is also shown a plain epoxy specimen for control. For the purpose of preliminary results, only 3 specimens were fabricated for each condition. All tensile specimens were tested in a model IKCL3-US13 Kratos machine, as per ASTM D 638 standard, at room temperature and strain rate of $10^{-5} \mathrm{~s}^{-1}$.

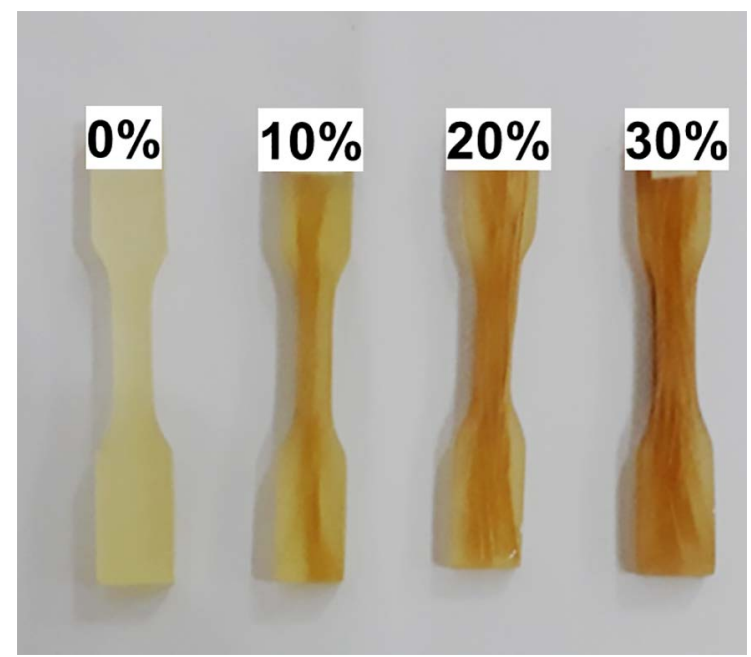

Figure 3. Typical plain epoxy and guaruman fiber reinforced composite tensile specimens.

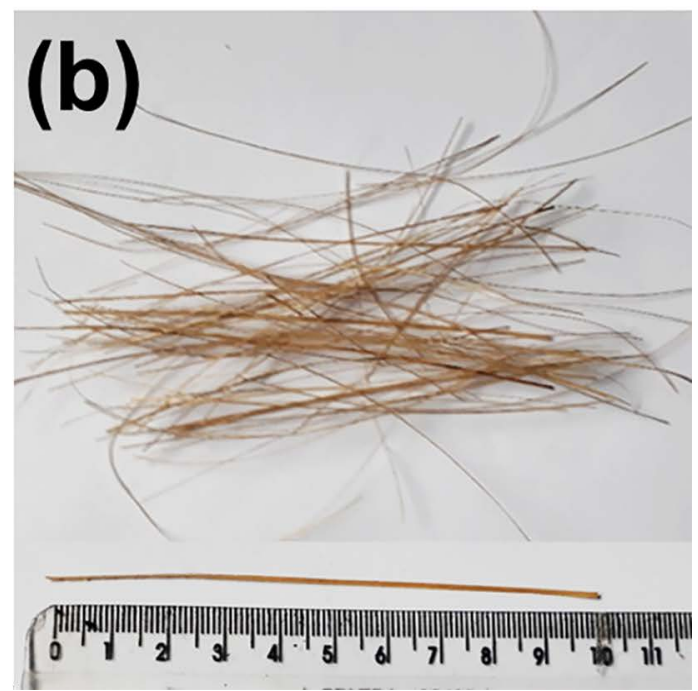

Figure 2. As received bundle of guaruman stems (a) and extracted fibers (b). 
Both the microstructural observation of the guaruman fibers and the fractograph analysis of the rupture surface of the tensile specimens were performed on a model TM 3000 Hitashi scanning electron microscope (SEM) operating with secondary electrons.

A cost-effective analysis was based on consumer prices of January 2019. A preliminary ballistic evaluation of guaruman epoxy composites as component of multilayered armor for personal protection was conducted at the center for Assessment of the Brazilian Army, CAEX, in Rio de Janeiro.

\section{Results and Discussion}

Figure 4 shows SEM micrographs of typical thinner, medium and thicker guaruman fibers. In this figure, it is important to notice that the thicker fiber, Fig. 4(c), with average diameter of $80 \mu \mathrm{m}$, displays a rougher surface with more voids and open areas as compare to the thinner fiber in Fig. 4(a). A statistical analysis of the guaruman fibers indicated $20 \%$ with diameter interval 20 to $40 \mu \mathrm{m} ; 53 \%$ with 40 to $60 \mu \mathrm{m}$; and $27 \%$ with 60 to $80 \mu \mathrm{m}$ corresponding to an average diameter of $52.4 \mu \mathrm{m}$.

Table 1 presents the mean density $\left(4 \mathrm{~m} / \pi \mathrm{d}^{2}\right)$ of guaruman fibers calculated for the three aforementioned diameter intervals.

In this table, one should notice that the thicker the fiber, the lower is its density. The reason for this behavior is directly related to the amount of voids and open areas observed with increasing the fiber diameter, as shown in Figure 4. In other words, a thinner fiber, Fig. 4(a), with less voids and open spaces pores, is accordingly denser. A proportional calculation for the average density based on the results in Table 1 revealed that a non-selected bunch of guaruman fibers have a mean value of $0.52 \mathrm{~g} / \mathrm{cm}^{3}$. This corresponds to one of the lightest known natural fibers ${ }^{29}$.
Table 1. Density of guaruman fibers for different diameter intervals.

\begin{tabular}{ccc}
\hline Thickness Interval & Average diameter $(\mu \mathrm{m})$ & Density $\left(\mathrm{g} / \mathrm{cm}^{3}\right)$ \\
\hline Thin & 30 & 0.69 \\
Medium & 50 & 0.48 \\
Thick & 70 & 0.37 \\
\hline
\end{tabular}

Figure 5 shows the tensile curves for the plain epoxy and the guaruman fiber reinforced composites. One may notice that two curves for the plain epoxy, Fig. 5(a), display a small amount of plastic deformation after the elastic region. By contrast, all curves for 10, 20 and 30 vol\% of guaruman fiber epoxy composites, Fig. 5(b), (c) and (d), respectively reveal a brittle behavior with rupture occurring right after the elastic region. These tensile curve results indicate that the incorporation of aligned guaruman fibers maintained the basic mechanical properties of the epoxy matrix, including the ductility. As further discussed, both cost and integrity in ballistic tests are specific advantages for using guaruman fibers in epoxy composites.

Based on the curves in Fig. 5, the tensile properties of the plain epoxy used as matrix as well as the guaruman fiber composites are presented in Table 2.

Figure 6 shows the variation of the tensile properties of plain epoxy and guaruman fiber reinforced epoxy composites as a function of the amount of fiber. An important point worth mentioning in this figure is the dispersion of values associated with the standard deviation (error bars). This is a consequence of the non-uniform structure of any natural lignocellulosic fiber ${ }^{1-23}$. However, higher dispersion is similarly observed for the plain epoxy matrix, which is also known for its wide interval of strength $(27-90 \mathrm{MPa})$ as well as total strain $(3-6 \%)^{30}$.
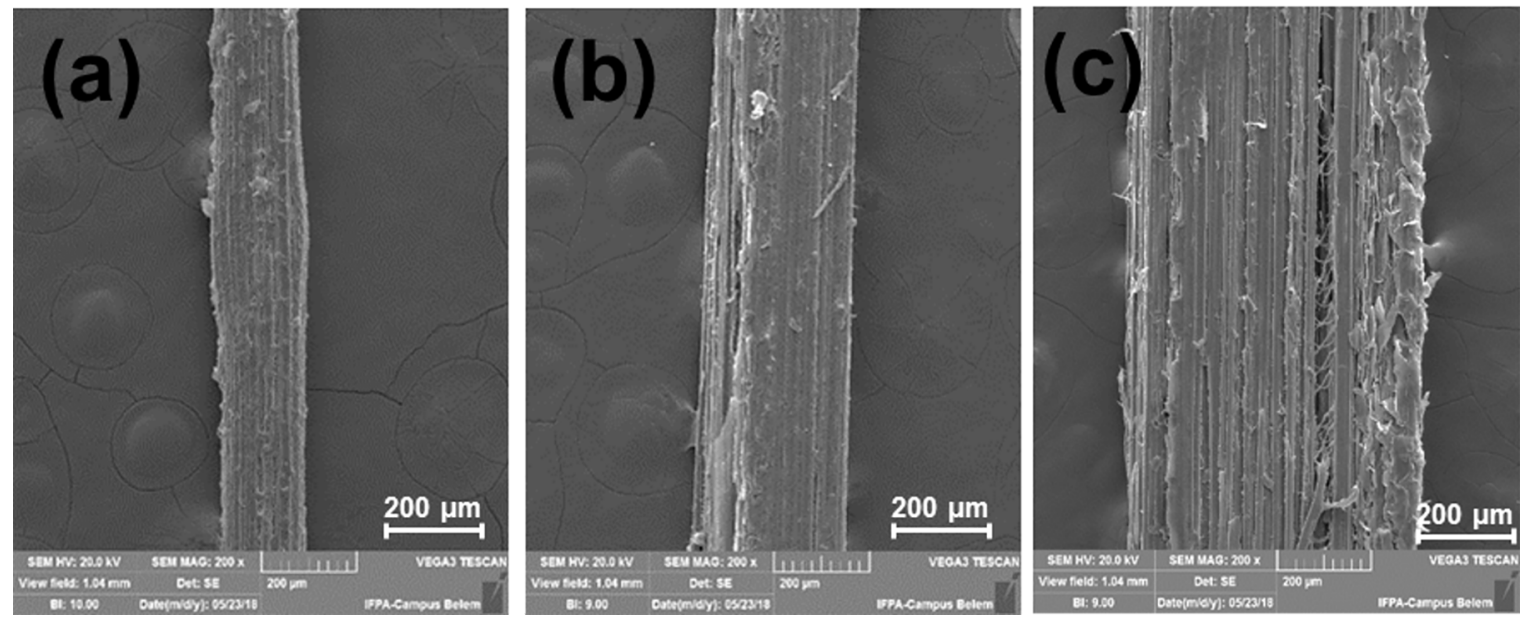

Figure 4. SEM micrographs of typical guaruman fibers (a) thin; (b) medium; and (c) thick diameter. 

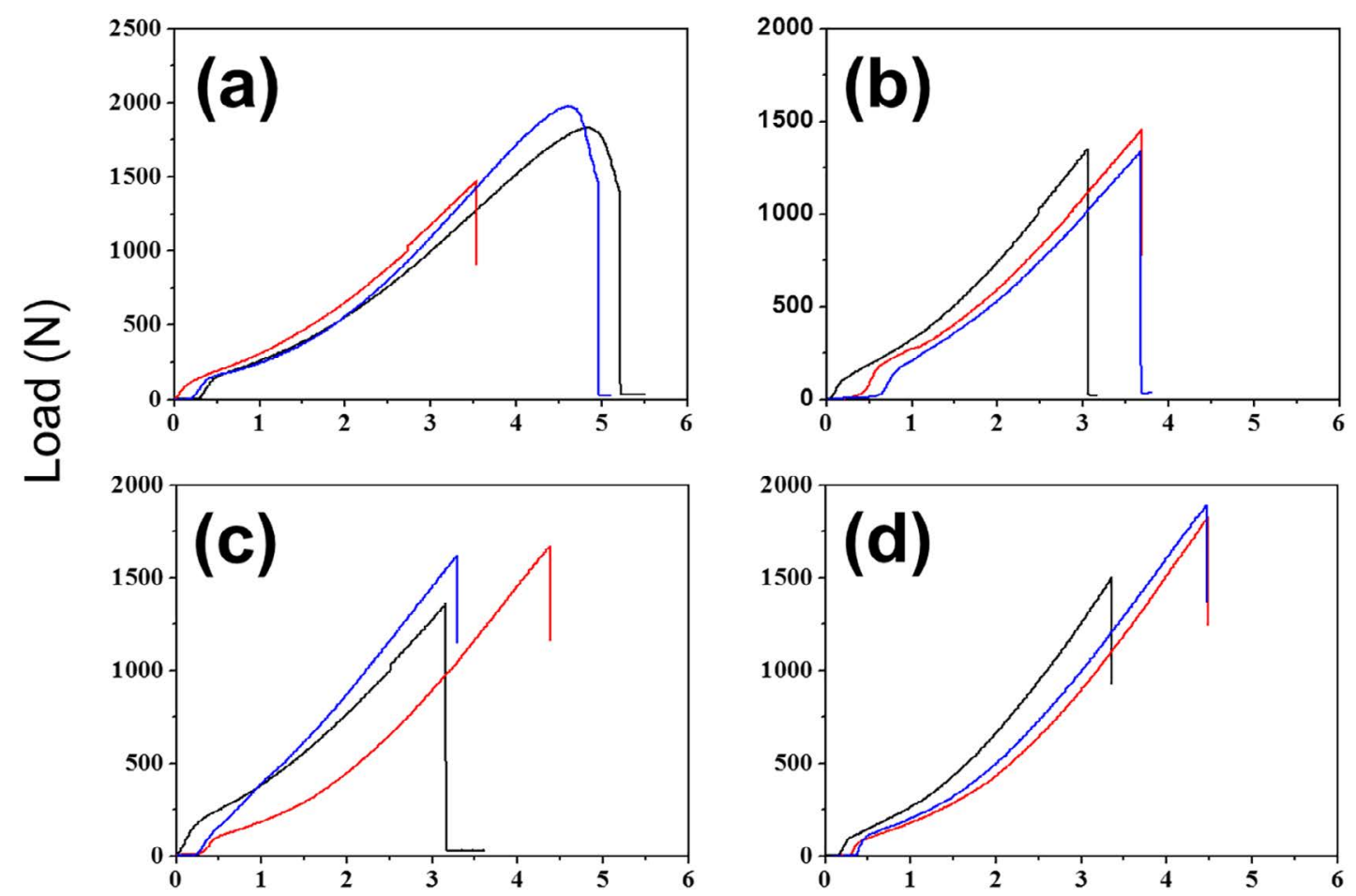

\section{Elongation $(\mathrm{mm})$}

Figure 5. Tensile load versus elongation curves for: (a) plain epoxy; (b) 10 vol\% guaruman fiber; (c) 20 vol\% guaruman fiber; and (d) $30 \mathrm{vol} \%$ guaruman fiber reinforced epoxy composites.
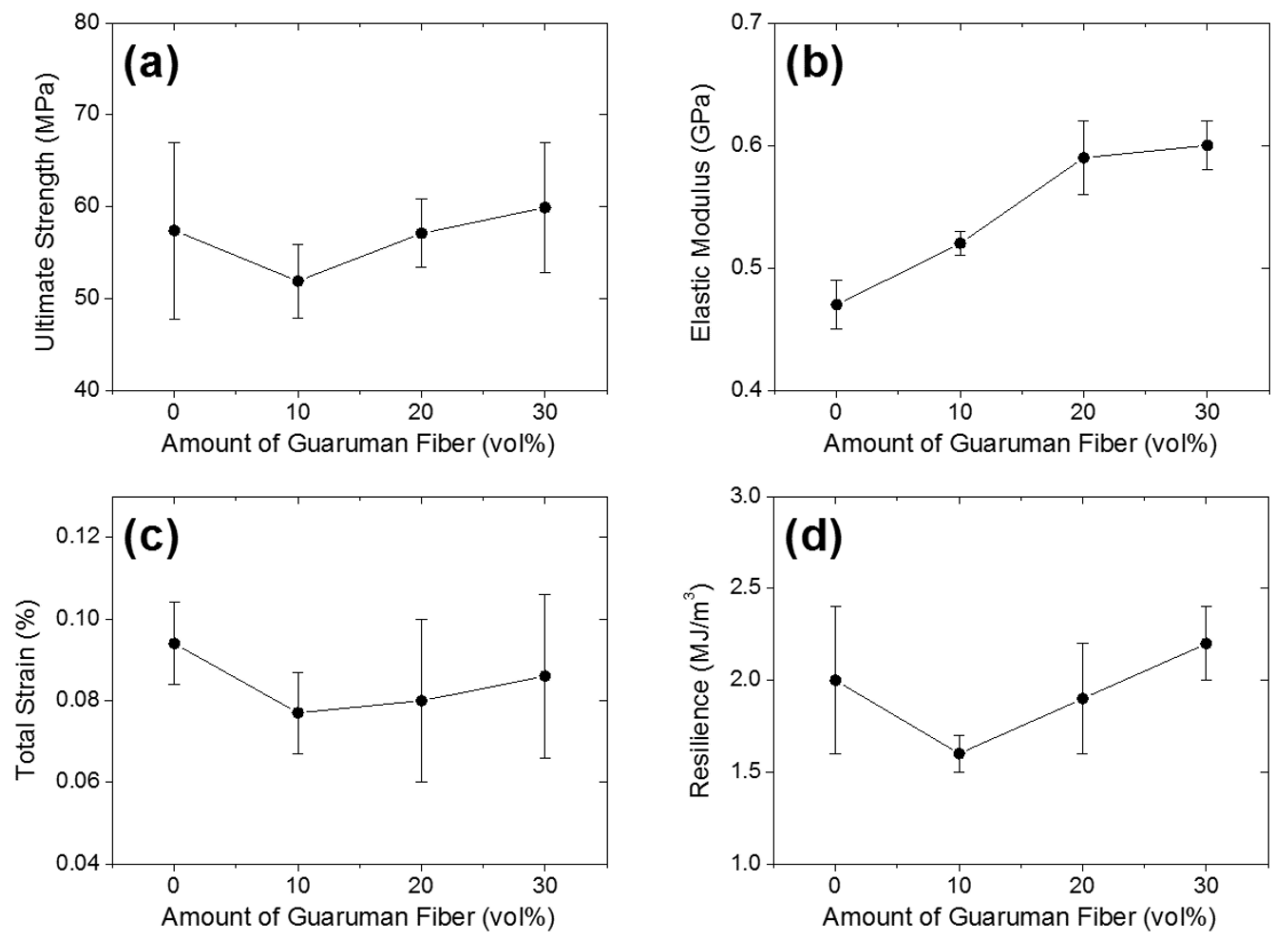

Figure 6. Variation with amount of guaruman fiber as reinforcement of epoxy composites of (a) ultimate strength; (b) elastic modulus; (c) total strain; and (d) resilience. 
Table 2. Tensile properties of control epoxy and guaruman fiber composites

\begin{tabular}{lcccc}
\hline \multirow{2}{*}{ Tensile Property } & \multicolumn{4}{c}{ Amount of Guaruman Fiber in Epoxy Composites } \\
\cline { 2 - 5 } & $0 \%($ Control $)$ & $10 \mathrm{vol} \%$ & $20 \mathrm{vol} \%$ & $30 \mathrm{vol} \%$ \\
\hline Ultimate Strength $(\mathrm{MPa})$ & $57.4 \pm 9.6$ & $51.9 \pm 4.0$ & $57.1 \pm 3.7$ & $59.9 \pm 7.1$ \\
Elastic Modulus $(\mathrm{GPa})$ & $0.47 \pm 0.02$ & $0.52 \pm 0.01$ & $0.59 \pm 0.03$ & $0.60 \pm 0.02$ \\
Total Strain $(\%)$ & $0.094 \pm 0.01$ & $0.077 \pm 0.01$ & $0.080 \pm 0.02$ & $0.086 \pm 0.02$ \\
Resilience $\left(\mathrm{MJ} / \mathrm{m}^{3}\right)$ & $2.0 \pm 0.4$ & $1.6 \pm 0.1$ & $1.9 \pm 0.3$ & $2.2 \pm 0.2$ \\
\hline
\end{tabular}

As for the ultimate strength in Fig. 6(a), the incorporation of guaruman fibers into the epoxy, within the error bars, does not provide a stronger reinforcement. By contrast, according to the results in Figure 6(b), the elastic modulus is slightly increased with the amount of fibers. This suggests that the guaruman fibers might enhance the composite stiffness, which is a commonly expected behavior in natural fiber reinforced polymer matrix composite ${ }^{17-19}$. Regarding the values of total strain, Fig. 6(c), and resilience, Fig. 6(d), the incorporation of guaruman fiber, within the statistics precision, does not affect the epoxy matrix behavior. The relatively restrict reinforcement provided by the guaruman fiber to the epoxy matrix is not a limitation for using these composites in several engineering applications. In fact, the values listed in Table 2 are acceptable for some parts and interior panels of automobiles ${ }^{24-26}$. In spite of practically no effect caused by the guaruman fiber on the tensile properties of epoxy composites, Fig. 6, a major economic advantage will be further discussed. Moreover, the importance of guaruman fibers in epoxy composites for ballistic applications will be also further addressed.

Relevant information on the mechanical behavior may also be recovered from the final fracture. Figure 7 depicts the macroscopic aspect of typical tensile ruptured specimens. In both conditions, Figure 7 (a) of the plain epoxy and Figure 7 (b) to (d) of the guaruman fiber composites, all specimens were broken inside the gauge length. Moreover, rupture occurred transversal to the tensile axis without necking or apparent signs of plastic deformation. An important point regarding the macroscopic aspects of specimens with 20 and $30 \mathrm{vol} \%$ of guaruman fibers, Fig. 7 (c) and (d), respectively, in the non-homogeneous distribution of fibers. Despite being aligned, some fibers tend to agglomerate, which may compromise the continuity of the fiber/epoxy interface. Consequently, voids and regions of stress concentration might exist. In principle, these heterogeneities could impair the guaruman fiber reinforcement effect in terms of lower values for the mechanical properties in Table 2 and wide error bars in Fig. 6.

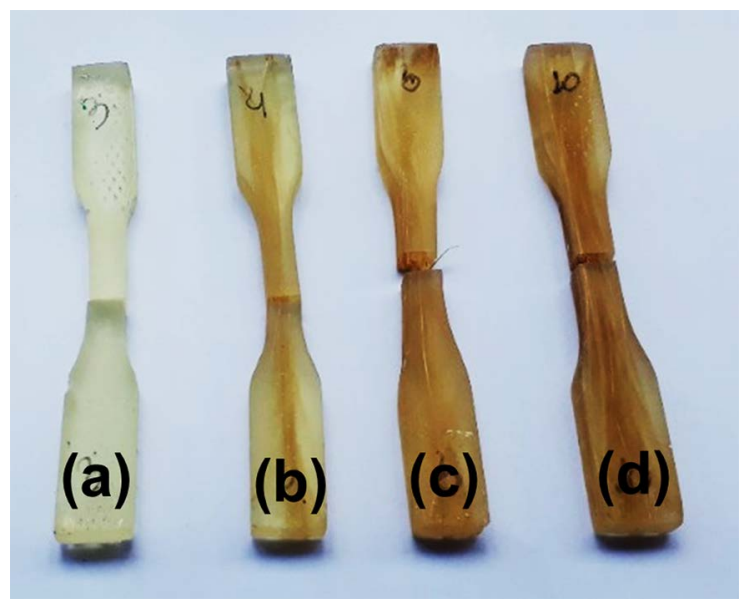

Figure 7. Macroscopic aspect of typical tensile ruptured specimens: (a) plain epoxy; (b) $10 \mathrm{vol} \%$ guaruman fiber; (c) 20 vol\% guaruman fiber; and (d) $30 \mathrm{vol} \%$ guaruman fiber reinforced epoxy composites.

SEM fractographs obtained from the ruptured surface of these tensile specimens are shown in Fig. 8. The images in this figure reveal some important aspects. First, it is confirmed that the epoxy fracture is brittle, Fig. 8(a), and displays marks (river patterns, pointed by arrow) characteristics of easy cracks propagation. Second, the composites exhibit partial adherence of the guaruman fibers to the epoxy matrix, as shown in Figure 8 (b) to (d). Actually, evidence of fiber pullout is also seen in the composite fracture. This pullout is associated with holes next to fibers indicated by arrows. Third, the guaruman fibers act as effective barriers to cracks that are propagating in the brittle epoxy matrix. This is observed as arrested river patterns in the inset of Fig. 8(d). The partial barrier provided by the guaruman fibers to crack propagation in the composite epoxy contributes to the reinforcement while the holes caused by pullout impair this reinforcement. Another relevant point limiting the fiber reinforcement is the possible agglomeration observed in Fig 7(c) and (d), which affects the adhesion to the epoxy matrix and facilitates the fiber pullout seen in Fig. 8. The balance resulting from partial fiber adherence and fiber pullout justifies the practically none or very small improvement in the tensile properties, 
Table 2 and Fig. 6, of the composites. On the other hand, a cost-effective analysis is highly favorable to the use of guaruman fibers in epoxy composites.

Table 3 presents a summary of the cost-effective analysis comparing the plain epoxy and the guaruman fiber composites. For this cost analysis, the basic material was considered with a total volume of $100 \mathrm{~cm}^{3}$ and the cost of epoxy, $12 \mathrm{US}$ dollars $/ \mathrm{kg}$, as an average market price in Brazil. As for the guaruman, there are no official values but fibers are sold at an average price around one US dollar/ $\mathrm{kg}$ in Belem (Para, Brazil). Based on the results of Table 1, the light guaruman fiber has an average density of $0.52 \mathrm{~g} / \mathrm{cm}^{3}$. From laboratory experiments, a plate of epoxy/ hardener was found to have a density of $1.08 \mathrm{~g} / \mathrm{cm}^{3}$.

The results in Table 3 reveal that a $30 \mathrm{vol} \%$ guaruman fiber reinforced epoxy composite presents, comparatively, a saving of $29 \%$ in cost to plain epoxy. For technological applications, this is a relevant result since the incorporation of guaruman fibers does not impair the tensile properties of the epoxy, as shown in Table 2 and Fig. 6. In other words, by supporting the mechanical behavior of epoxy, the much cheaper and environmentally friendly guaruman fiber is a viable alternative for composite reinforcement competing with other natural fibers ${ }^{17-19,29}$. Similar to curaua ${ }^{6,29,30}$, the guaruman fiber might be particularly relevant for the economy and technological development of the north region of Brazil.

Finally, a preliminary investigation on the ballistic performance of a $30 \mathrm{vol} \%$ guaruman fiber reinforced epoxy composite disclosed a potential for application as component of a multilayered armor system (MAS) for personal protection against $7.62 \mathrm{~mm}$ caliber rifle ammunition. As an advantage, the epoxy composite reinforced with $30 \mathrm{vol} \%$ of fibers stays integer after the first bullet impact and is able to resist multiple shooting required by the standard ${ }^{35}$.

Table 3. Comparative cost-effective analyses for plain epoxy and guaruman fiber epoxy matrix composites. (Based on $100 \mathrm{~cm}^{3}$ of material and consumer prices.)

\begin{tabular}{ccccc}
\hline Material $\left(100 \mathrm{~cm}^{3}\right)$ & Weight $(\mathrm{g})$ & Partial Cost $($ US dollar) & Total Cost (US dollar) & Reduced Cost (\%) \\
\hline Plain Epoxy & $100 \times 1.08=108$ & $0.108 \times 12=1.296$ & 1.296 & Control (Zero) \\
10 vol\% Fiber & $10 \times 0.52=5.2$ & $0.0052 \times 1=0.005$ & 1.171 & 10 \\
90 vol\% Epoxy & $90 \times 1.08=97.2$ & $0.0972 \times 12=1.166$ & & 19 \\
20 vol\% Fiber & $20 \times 0.52=10.4$ & $0.0104 \times 1=0.010$ & 1.047 & 29 \\
80 vol\% Epoxy & $80 \times 1.08=86.4$ & $0.0864 \times 12=1.037$ & & \\
30 vol\% Fiber & $30 \times 0.52=15.6$ & $0.0156 \times 1=0.016$ & 0.923 & 29 \\
70 vol\% Epoxy & $70 \times 1.08=75.6$ & $0.0756 \times 12=0.9072$ & &
\end{tabular}
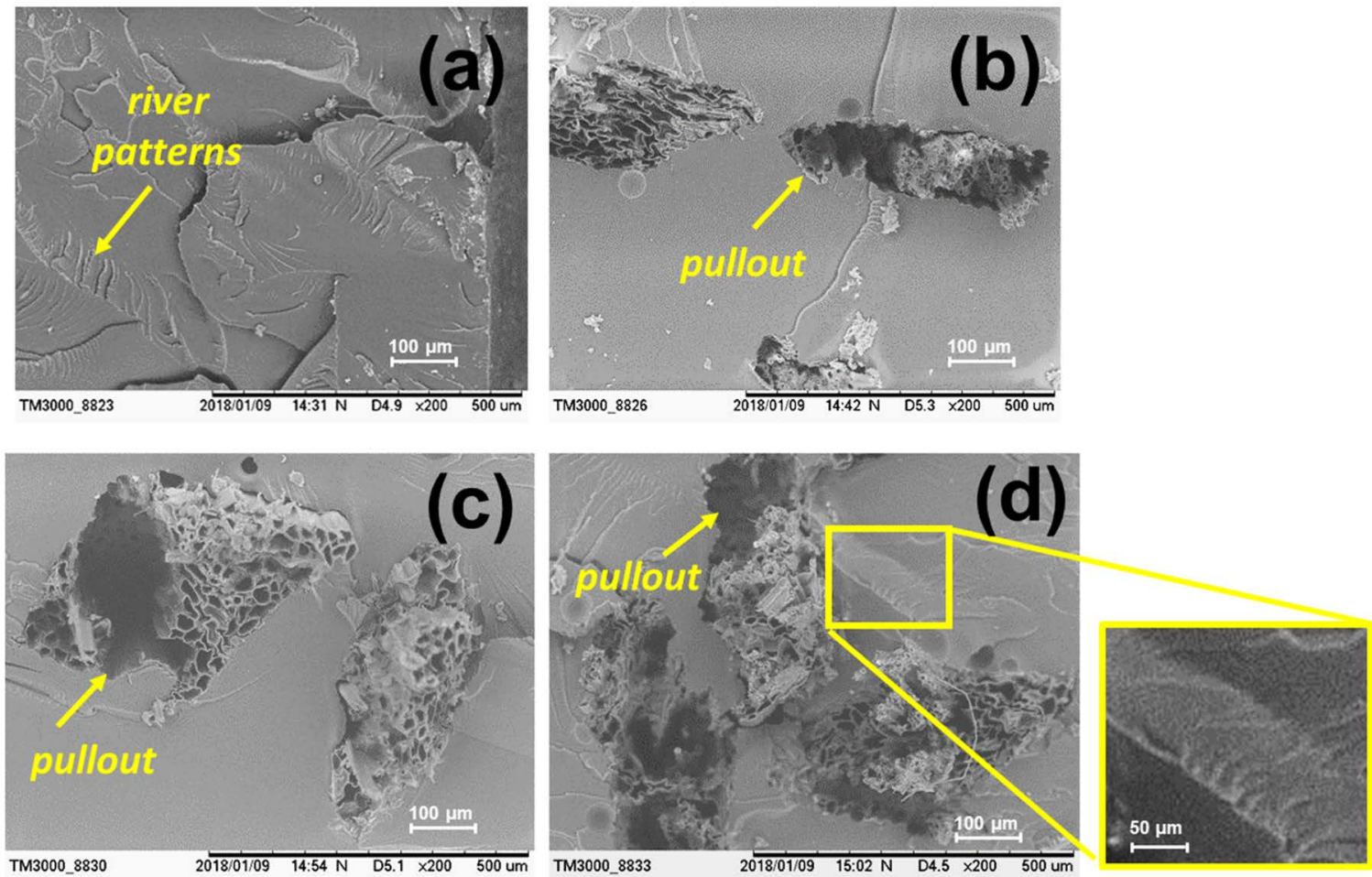

Figure 8. SEM fractographs of typical tensile ruptured specimens: (a) plain epoxy; (b) 10 vol\% guaruman fiber; (c) 20 vol\% guaruman fiber; and (d) $30 \mathrm{vol} \%$ guaruman fiber reinforced epoxy composites. 
Composites with lower amounts of guaruman fibers are broken by the first shooting. Composites with higher amounts are difficult to process due to excessive fiber agglomeration, which impairs adhesion. Indeed, as MAS second layer, after a front ceramic, the $30 \mathrm{vol} \%$ guaruman composite plate performed in a comparable way to conventional Kevlar ${ }^{\mathrm{TM}}$ plate with same thickness. This ballistic performance was also reported for well-known natural fibers used as reinforcement of engineering composites ${ }^{36}$.

\section{Conclusions}

- For the first time a relatively unknown natural fiber, extracted from the guaruman plant cultivated in the Amazonian region of Brazil, was investigated as reinforcement of epoxy matrix composites.

- The mean density of $0.52 \mathrm{~g} / \mathrm{cm}^{3}$ measured for the guaruman fiber is among the lowest reported so far for any natural fiber.

- Practically no significant variation in the tensile properties of the epoxy matrix was caused by incorporation up to $30 \mathrm{vol} \%$ of guaruman fibers.

- However, a cost-effective analysis revealed that incorporation of guaruman fibers significantly reduced the price of epoxy composites with saving reaching $29 \%$ for a composite with $30 \mathrm{vol} \%$ of fibers.

- Preliminary ballistic tests disclosed a potential application of $30 \mathrm{vol} \%$ guaruman fiber epoxy composites as component of multilayered armor for personal protection against high impact riffle bullets. This composite stays intact after a first hit and is expected to attend standard multiple shootings requirement.

\section{Acknowledgements}

The authors thank the support to this investigation by the Brazilian agencies: CNPq, FAPERJ and CAPES.

\section{References}

1. Mohanty AK, Misra M, Hinrichsen G. Biofibres, biodegradable polymers and biocomposites: An overview. Macromolecular Materials and Engineering. 2000;276-277(1):1-24.

2. Mohanty AK, Misra M, Drzal LT. Sustainable Bio-Composites from Renewable Resources: Opportunities and Challenges in the Green Materials Word. Journal of Polymers and the Environment. 2002;10(1-2):19-26.

3. Netravali AN, Chabba S. Composites get greener. MaterialsToday. 2003;6(4):22-29.

4. John MJ, Thomas S. Biofibers and biocomposites. Carbohydrate Polymers. 2008;71(3):343-364.

5. Satyanarayana KG, Arizaga GGC, Wypych F. Biodegradable composites based on lignocellulosic fibers - An overview. Progress in Polymer Science. 2009;34(9):982-1021.
6. Monteiro SN, Lopes FPD, Ferreira AS, Nascimento DCO. Natural fiber polymer-matrix composites: Cheaper, tougher and environmentally friendly. JOM. 2009;61(1):17-22.

7. Summerscales J, Dissanayake NPJ, Virk AS, Hall W. A review of blast fibers and their composites. Part 1 - Fibers as reinforcement. Composites Part A: Applied Science and Manufacturing. 2010;41(10):1329-1335.

8. Summerscales J, Dissanayake NPJ, Virk AS, Hall W. A review of blast fibers and their composites. Part 2 - Composites. Composites Part A: Applied Science and Manufacturing. 2010;41(10):1336-1344.

9. Zini E, Scendola M. Green Composites - An overview. Polymer Composites. 2011;32(12):1905-1915.

10. La Mantia FP, Morreale M. Green composites: A brief review. Composites Part A: Applied Science and Manufacturing. 2011;42(6):579-588.

11. Ku H, Wang H, Pattarachayakoop N, Trada M. A review on tensile properties of natural fiber reinforced polymer composites. Composites Part B: Engineering. 2011;42(4):856-873.

12. Faruk O, Bledzki AK, Fink HP, Sain M. Biocomposites reinforced with natural fibers: 2000-2010. Progress in Polymer Science. 2012;37(11):1552-1596.

13. Shah DU. Developing plant fiber composites for structural applications by optimizing composite parameters: A critical review. Journal of Materials Science. 2013;48(18):60836107.

14. Thakur VK, Thakur MK, Gupta RK. Review: Raw Natural Fibers-Based Polymer Composites. International Journal of Polymer Analysis and Characterization. 2014;19(3):256-271.

15. Faruk O, Bledzki AK, Fink HP, Sain M. Progress report natural fiber reinforced composites. Macromolecular Materials and Engineering. 2014;299(1):9-26.

16. Mohammed L, Ansari MNM, Pua G, Jawaid M, Islam MS. A Review on Natural Fiber Reinforced Polymer Composites and Its Applications. International Journal of Polymer Science. 2015;2015:243947. DOI: 10.115/2015/243947

17. Güven O, Monteiro SN, Moura EAB, Drelich JW. Re-Emerging Field of Lignocellulosic Fiber - Polymer Composites and Ionizing Radiation Technology in Their Formulation. Polymer Reviews. 2016;56(4):702-736.

18. Pickering KL, Efendy MGA, Le TM. A review of recent developments in natural fiber composites and their mechanical performance. Composites Part A: Applied Science and Manufacturing. 2016;83:98-112.

19. Sanjay MR, Madhu P, Jawaid M, Senthamaraikannan P, Senthil S, Pradeep S. Characterization and properties of natural fiber polymer composite: A comprehensive review. Journal of Cleaner Production. 2018;172:566-581.

20. Bledzki AK, Sperber VE, Faruk O. Natural and Wood Fibre Reinforcement in Polymers. Shrewsbury: Rapra Technology; 2002.

21. Mohanty AK, Misra M, Drzal LT, eds. Natural Fibers, Biopolymers, and Biocomposites. Boca Raton: CRC Press; 2005.

22. Pickering K, ed. Properties and Performance of Natural-Fibre Composites. Boca Raton: CRC Press; 2008. 
23. Kalia S, Kaith BS, Kaur I, eds. Cellulose Fibers: Bio- and Nano-Polymer Composites. New York: Springer; 2011.

24. Marsh G. Next step for automotive materials. MaterialsToday. 2003;6(4):36-43.

25. Holbery J, Houston D. Natural-fiber-reinforced polymer composites applications in automotive applications. JOM. 2006;58(11):80-86.

26. Alves C, Ferrão PMC, Silva AJ, Reis LG, Freitas M, Rodrigues $\mathrm{LB}$, et al. Eco design of automotive components making use of natural jute fiber composites. Journal of Cleaner Production. 2010;18(4):313-327.

27. Dittenber DB, GangaRao HVS. Critical review of recent publications on use of natural composites in infrastructure. Composites Part A: Applied Science and Manufacturing. 2012;43(8):1419-1429.

28. Krishna NK, Prasanth M, Gowtham R, Karthie S, Mini KM. Enhancement of properties of concrete using natural fibers. MaterialsToday: Proceedings. 2018;5(11 Pt 3):23816-23823.

29. Monteiro SN, Lopes FPD, Barbosa AP, Bevitori AB, da Silva ILA, da Costa LL. Natural Lignocellulosic Fibers as Engineering Materials - An Overview. Metallurgical and Materials Transactions A. 2011;42:2963-2974.
30. Callister WD Jr., Rethwisch DG. Materials Science and Engineering. An Introduction. $9^{\text {th }}$ ed. Hoboken: John Willey \& Sons; 2014.

31. Pappu A, Patil V, Jain S, Mahindrakar A, Haque R, Thakur VK. Advances in industrial prospective of cellulosic macromolecules enriched banana biofibre resources: A review. International Journal of Biological Macromolecules. 2015;79:449-458.

32. Thakur MK, Thakur VK, Gupta RK, Pappu A. Synthesis and Applications of Biodegradable Soy Based Graft Copolymers: A Review. ACS Sustainable Chemistry \& Engineering. 2015;4(1):1-17.

33. Pappu A, Saxena M, Thakur VK, Sharma A, Haque R. Facile extraction, processing and characterization of biorenewable sisal fibers for multifunctional applications. Journal of Macromolecular Science, Part A: Pure and Applied Chemistry. 2016;53(7):424-432.

34. Pappu A, Thakur VK. Towards sustainable micro and nano composites from fly ash and natural fibers for multifunctional applications. Vacuum. 2017;146:375-385.

35. National Institute of Justice. Ballistic Resistance of Body Armor - NIJ Standard-0101.06. Washington: US Department of Justice; 2008.

36. Benzait $Z$, Trabzon L. A review of recent research on materials used in polymer-matrix composites for body armor application. Journal of Composite Materials. 2018;52(23):3241-3263. 